\title{
New in the theory and practice of socialization of the young US in the beginning of the "digital century" Veselova V.
}

\author{
Новое в теории и практике социализации молодежи США в начале \\ «цифрового столетия» \\ Веселова В. В.
}

\author{
Веселова Валерия Валентиновна / Veselova Valerija - кандидат педагогических наук, доцент, \\ Научно-исследовательский центр \\ Московский психолого-социальный университет, г. Москва
}

\begin{abstract}
Аннотация: в статье рассматриваются вопросы социализации молодежи США, решающим фактором в которой становятся информационно-коммуникаиионные технологии (ИКТ). Охарактеризованы основные направления данного процесса, связанные с геймификацией образа жизни, и внедрения инструментов виртуальной реальности в систему образования.

Abstract: the article presents the issues of socialization of youth of the United States. A crucial factor is high technology, especially information and communication (ICT). The main directions of this process are related to the gamification of lifestyle and introduction of virtual reality tools in education concerning skills for social progress.
\end{abstract}

Ключевые слова: социилизачия, информационно-коммуникациионные технологии (ИКТ), ичифровая революция, компетенщии успешного человека, когнитивные технологии, эмочиональный интеллект, геймификация, виртульная реальность.

Keywords: socialization, information and communication technology (ICT), gamification, virtual reality, emotional intelligence, skills for social progress.

Публикачия подготовлена в рамках поддержанного РГНФ проекта № 15-06-10102a

Двадцать пять лет назад, в августе 1991 года, во Всемирную паутину (WWW) - интернет вошли первые пользователи, открывшие «цифровую эру», которая кардинально изменила все наши представления и образ жизни. Создатель интернета, сэр Бернерс-Ли, в обращении ко всем пользователям сети по случаю юбилея вспоминает, что его руководитель, ознакомившись с идеей проекта, произнес слова, достойные стать мемом: «Расплывчато, но интересно!». Система интернета, «расплывшаяся» по всему свету, принесла миллиарды долларов в мировую экономику, превратила информацию в золотую валюту XXI века, запустила инновационные технологии в системы образования, здравоохранения и практически во все сферы жизни, преодолев границы и расстояния. Если рассматривать это событие в контексте исторического времени, переход к новому технологическому укладу совершился мгновенно. Согласно статистическим данным на 30 июня 2016 г. [1], интернетом пользуются 98,2\% жителей Исландии, 96\% - Дании, 96,3\% - Норвегии, 91\% - Японии, 88,6\% - США, 70,5\% - России. Ожидается, что к 2020 году в мире будет 2,95 миллиарда пользователей сети. В «Докладе о мировом развитии-2016», подготовленном Всемирным банком, констатируется, что мир переживает величайшую информационнокоммуникационную революцию в истории человечества. Технологические перемены, которые сравнимы с промышленной революцией XVIII века, позволили 40 процентам населения планеты получить доступ к интернету. Однако при этом около 4 миллиардов людей, почти 60 процентов мирового населения, не имеют доступа к сети, а это означает, что они обречены на отставание в экономическом и культурном развитии [2]. Это означает также, что появился новый вид неравенства - цифровое неравенство - с далеко идущими последствиями. Следует добавить, что помимо информационных, в нашу жизнь вошли еще три великие технологии - когнитивные, нано- и биотехнологии. Их взаимовлияние и взаимопроникновение, результаты этой конвергенции миру еще предстоит осмыслить.

Будущее образования обсуждается в глобальном масштабе. Новый тип коммуникаций преобразовал мировое образовательное пространство в наднациональное, причины появления которого обоснованы в научных трудах И. А. Тагуновой [3]. Организация по экономическому сотрудничеству и развитию, в которой состоят 34 государства, включая США, представило свои рекомендации по подготовке молодежи к жизни. Рассматривались такие вопросы как образование, рынок труда, здоровье, семейная жизнь, гражданская активность и удовлетворенность человека качеством жизни. Установлено, что уверенную встречу вызовов XXI века молодому человеку обеспечит набор определенных умений, включающих в себя умение добиваться намеченной цели; эффективно сотрудничать с окружающими и владеть собой; а также ряд других, о чем мы подробнее будем говорить ниже, представляя несколько программ социализации [4].

В 2013 г. Президент США Б. Обама выступил с призывом привести всех американских учащихся в «цифровое столетие» с помощью высокоскоростного интернета и новейших технологий [5]. Главная 
цель данного начинания состоит в том, чтобы содействовать получению навыков, которые в будущем помогут выпускникам найти хорошую работу, занять достойное положение в обществе, а стране сохранить лидирующее положение в мире. Американский Президент напрямую связал конкурентоспособность США с кадрами, соответствующими запросам современной экономики. Большой бизнес внес свой вклад в решение общенациональной задачи. Например, компания «Аррlе» выделила 100 миллионов долларов и обеспечила каждого ученика планшетником, а каждого учителя - ноутбуком и компьютером в 114 школах, над которыми взяла шефство. Каждый класс был подключен к телевизионной сети компании, в которой группа высококвалифицированных специалистов разрабатывает специальные учебные приложения, платформы, программы по запросам школ, ведет постоянные консультации для детей и учителей, мониторит учебно-воспитательные процессы.

Эпоха высоких технологий требует пересмотра всей системы знаний и умений человека. В число необходимых выдвинулась цифровая (компьютерная) грамотность, вставшая в один ряд с навыками чтения, письма и счета. В ряде американских штатов принято решение о выдаче специальных сертификатов (по образцу водительских удостоверений), удостоверяющих квалификацию пользователя. Не имея такого сертификата, человек едва ли может претендовать на высокооплачиваемую работу. Тем более, что конкуренцию ему составят так называемые «цифровые туземцы», поколения детей, родившихся с гаджетами в руках! Они росли с планшетниками, познавая жизнь через образовательные и развлекательные приложения. Это новые поколения, которые проводят в виртуальной реальности около половины своего свободного времени. Эти люди привыкли получать информацию по цифровым каналам, им неинтересны бумажные носители по целому ряду причин. Во-первых, они не столь красочны, как интерфейсы; во-вторых, они не интерактивны. Точнее, чтобы взаимодействовать с книжным текстом, необходимы умственные усилия, приходится задумываться, искать аналогии, связи, подключать воображение и прочее. В-третьих, темп чтения нетороплив. Для новых поколений книги просто скучны, так как особенность их мышления состоит в краткосрочных действиях, требующих мгновенной оценки; мультизадачности; скорости впечатлений; смены сюжетов. По поводу многозадачности существует определенный разброс мнений, для вынесения суждения об эффективности данного вида деятельности пока недостаточно материала. Можно сослаться на новейшее исследование, проведенное психологами в г. Портленде (США). Ученые установили, что «цифровые туземцы» 10-19 лет проявляют бОльшую продуктивность в режиме многозадачности, у них выработалась способность к расширению рабочей памяти. Они также лучше справляются с задачами в отвлекающих условиях [6]. Неслучайно такой популярностью пользуется Snapchat (Снэпчат), программное обеспечение для мгновенного обмена фото и видео, которые самоуничтожаются через несколько секунд после просмотра. По статистике на май 2014 г. пользователи этого приложения отправляли по 700 миллионов фото и видео в день, а контент раздела «Сюжеты» просматривался ежедневно по 500 миллионов раз. Девиз этого популярного приложения краток «Живи веселей и не парься!» [7].

Слияние с компьютером - это новая стадия нашего существования, а социальные сети - новая форма жизни. В сети есть блоги, влоги (видеоблоги) - их авторов, набравших большое число подписчиков, привлекают к сотрудничеству производители товаров, услуг и рекламодатели. Именно эти люди становятся примерами для подражания, влияют на мировоззрение молодежи и становятся акторами в процессе социализации. Создатели интернета считали, что самый важный вклад сети в жизнь человека состоит в том, что каждый из нас может быть не только потребителем, но и создателем информации и знаний. Оказалось, что получив возможность и право голоса, люди стали говорить исключительно о себе, здесь в полной мере проявился человеческий эгоцентризм, а апогеем его явилось «селфи», которое в 2013 году стало самым популярным в мире словом.

По мере того, как ИКТ проникают в социальную жизнь, у родителей, педагогов, психологов накапливаются наблюдения и опасения. В основном они выражаются в следующем: отмечено, что с течением времени как у детей, так и у взрослых возникает привыкание, а затем и зависимость от гаджетов. Нередко она выражена в тяжелой форме и требуется «цифровой детокс», необходимо лечение, которое поможет избавиться от пагубного пристрастия. В ряде стран есть кафе, рестораны, отели, где пользоваться гаджетами категорически запрещается, и посетители сдают их на хранение администрации. В связи с тем, что влияние стремительно меняющихся кадров виртуальной реальности на психику человека пока недостаточно изучено, но уже имеет место, возникают вопросы не только медицинского, но и этического характера. Сюжеты видеоигр могут быть сконструированы так, чтобы вызвать интерес, эмпатию, радость, то есть вызывать и формировать просоциальные эмоции. Но ведь с тем же успехом можно формировать и асоциальные стремления? Вполне возможно моделировать эмоции незаметно для человека, который остается в полной уверенности, что «все под контролем», в то время как его тонко и умело «переформатируют», меняют установки и ориентиры. Кроме того, создатели игр весьма преуспели и в коммерческой эксплуатации игроков. Сфера образования - один из главных объектов обслуживания для гигантской индустрии современных средств связи. Специально для учебных заведений выпускается аудио- и видеопродукция высокого класса с учетом возрастных особенностей клиентов. Это 
интерактивные игры, программы, учебники, методические пособия, мультиплатформы. Огромное количество вспомогательных материалов разрабатывается в соответствии с новейшими научными рекомендациями. Более того, маркетологи изучают спрос, а разработчики, уже с учетом его тенденций, заказами отдельных штатов и даже школьных округов его удовлетворяют. Новинка текущего года специальные очки для погружения в виртуальную реальность. Можно опуститься в подводный мир или полететь на Марс, можно повторить путешествие Одиссея, можно даже оказаться в офисе взорванного небоскреба и ощутить эмоции погибающего человека. В этом году ожидается покупка восьми миллионов таких очков. Психологи предупреждают, что младших школьников не следует допускать к таким играм, и советуют проводить тестирование неустойчивой подростковой психики на свето-, водо- и высотобоязнь, дабы не закрепить фобии на всю жизнь.

В начале 2000-х годов в США начался период геймификации (игрофикации) - применения подходов, которые используются в компьютерных играх, чтобы стимулировать деятельность участников в неигровых процессах. Поясним, на каких психологических механизмах основаны геймификация. Известный американский игротехник Ю-кай Чоу разработал модель факторов, которые усиливают мотивацию любого вида деятельности человека. Каждым из нас движет уникальное сочетание таких факторов, их можно выявить и просчитать, а потом использовать в намеченных целях. В связи с этой достаточно эффективной методикой постоянно возникает вопрос: что это, мотивация или манипуляция? Автор доказывает, что его методика приносит человечеству пользу на примере игры с пазлами «Сверни его». В 2013 г. с помощью этой игры был совершен прорыв в исследовании Спида. В течение 15 лет ученые бились над проблемой свертывания белка. 240 тысяч участников игры-головоломки, пробуя различные варианты-комбинации пазлов, решили эту задачу за 10 дней и помогли создать новый препарат [8]. Ю-кай Чоу помогает детям и взрослым познавать мир самым радостным образом - играя. Интерактивные ролевые игры основаны на взаимодействии, слаженной работе в команде, на точности в использования ресурсов, правильной стратегии в принятии решений. В ходе такой игры происходит обучение в социуме: люди переживают личный, индивидуальный опыт, он меняется в зависимости от партнеров. Игроки обмениваются знаниями, планами, гипотезами, сомнениями, переживаниями, они учатся друг у друга. Они играют, но при этом приобретают реальные знания и опыт, который смогут применить в жизни. Геймификация превратилась в одну из значимых форм социализации, а игровые навыки перешли в разряд базовых.

В программы подготовки детей к будущему стали включать такое понятие, как жизнестойкость. Человеку, живущему в меняющемся обществе, нужно уметь справляться с невзгодами, ладить с окружающими, сохранять самообладание, разумно планировать свои действия и находить решения проблем. Частично этому способствует геймификация, но расскажем еще об одной методике для школьников. Она состоит из пяти правил, согласно которым формируется характер. 1) Выстраивайте добрые взаимоотношения с людьми и в семье, и вне ее. 2) В каждой трудности учитесь находить что-то хорошее и полезное; часто бывает, что в преодолении обстоятельств люди находят новых друзей, а в себе открывают ранее скрытые способности. 3) Будьте оптимистами. Надежда и оптимизм помогают видеть светлые грани жизни. Случаются тяжелые ситуации, некоторые обстоятельства мы не в силах изменить, но по-новому взглянуть на них всегда возможно. 4) Будьте решительны. Не надейтесь, что все разрешится «само собой», принимайте решение и действуйте. Специально изучайте методику принятия решений, чтобы видеть возможные варианты. 5) Поймите одну важную вещь: перемены - неотъемлемая и неизбежная составляющая жизни. Ваша задача - не избегать неприятностей, боли и потерь, а научиться переносить их с достоинством [9].

Согласно этой методике социализация происходит с участием когнитивных технологий, которые развивают рефлексию и те качества, о которых речь шла выше. Те же технологии помогают проводить программы обучения молодежи финансовой грамотности, чего долго добивались родители. Действительно, эти знания следует также отнести к базовым. Учащиеся должны получить знания и навыки в сфере инвестирования и сбережений. Личные финансы - это не чековая книжка и сбережения «на черный день», как было ранее. В цифровом обществе большинство финансовых операций, трансакций совершается мгновенно, онлайн. Идеи, сервисы, даже комментарии и критические замечания также приобрели рыночную стоимость. В наше время недостаточно усердно трудиться и зарабатывать деньги, надо заставить их работать на вас, а для этого необходимо их выгодно инвестировать. Именно инвестирование является основным источником аккумулирования и поддержания благосостояния нации [10]. Следующим шагом в развитии финансовых технологий станет введение криптовалюты. Бумажные деньги, банкноты постепенно заменяются пластиковыми накопителями, а в интернете получила хождение цифровая валюта - биткоин. В США и ряде западных стран появились биткоин-автоматы, в некоторых магазинах эту валюту принимают для оплаты товаров и услуг. С распространением криптовалюты водораздел между теми, кто приобщен к «цифровому миру», и теми, кто живет за его пределами, только вырастет. 
Эйфория от применения технологий прошла довольно скоро, и проявилась потребность общества в гуманизации взаимоотношений, во внимании к внутреннему миру человека, в сочетании эмоций с интеллектом. Дэниел Гоулман разработал теорию эмоционального интеллекта и доказал, что его можно и нужно развивать и совершенствовать с помощью специальных программ и упражнений. В дальнейшем ученый выделил важную роль внимания в личностном развитии человека и недавно выпустил книгу по данной проблеме [11]. В ней обозначены три типа фокусов нашего внимания. Первый - самосознание отвечает за наше личное благополучие. Мы должны чутко относиться ко всем сигналам своего тела, чтобы не пропустить болезнь; ко всем своим чувствам и эмоциям, чтобы жить наполненной жизнью. Второй тип фокуса - эмпатия - связан со способностью безоценочно воспринимать чувства других людей, сопереживать им, даже если мы не можем их разделить. Без чувства эмпатии не удастся жить в согласии с окружающими. Третий тип фокуса - внешний - определяет способность видеть скрытые связи между разными сферами жизни, понимать, как решения, принимаемые «здесь и сейчас», могут повлиять на отдаленные во времени и пространстве события. Успешные люди, как правило, хорошо разбираются в своем деле, сосредоточены на деятельности, быстро усваивают новую информацию, акцентируют внимание только на важных обстоятельствах. Программы по развитию эмоционального интеллекта практикуются во многих учебных заведениях США. Внедрение инновационных технологий в систему образования позволяет успешно решать несколько задач: повысить активность и сотрудничество учащихся; подобрать обучающий материал в полном соответствии с потенциальными возможностями учащихся и вести постоянное наблюдение за его деятельностью и развитием, внося необходимые коррективы; связывать учебно-познавательную деятельность с реальной жизнью через систему проектов; стимулировать учащихся, повышать их мотивацию с помщью мгновенных поощрений за достигнутые результаты. Применение ИКТ на практике доказало свою эффективность в развитии креативности, навыков критического мышления, решения проблем, межличностного общения.

Возможности интернета по социализации и развитию человека безграничны. В сетевом хранилище, Интернет-архиве, собираются данные о нашей цивилизации. В 2005 г. был открыт общественный проект «Открытая библиотека» по сканированию всех книг мира, в феврале 2010 г. в открытом доступе там находилось уже более полутора миллиона книг.

Цифровые технологии позволяют не только воспроизводить произведения культуры, артефакты, отправляться в путешествия, создавать предметы, менять способы коммуникации. Они меняют наше мировосприятие и дают возможность испытать несколько идентичностей. Наши личные страницы, комментарии, селфи и репосты в социальных сетях - это способы самоидентификации и репрезентации. Технологии электронных платежей умножили наши потребительские возможности. Пользователи интернета добровольно собрались под его «крышу» в виде облачных хранилищ информации и доверили ему доступ ко всем своим личным данным. Глобальная электронная система, объединившая колоссальные объемы информации, может быть использована как во благо, так и во зло. Но система это только инструмент, и только от человека зависит, как он будет использован [12].

Подводя итоги обзору новейших тенденций в социализации американской молодежи, отметим следующее: в стране сформулированы четкие представления о компетенциях успешного человека XXI века. Успешность рассматривается с точки зрения его вклада в экономику государства и обепечения ее высокой конкурентоспособности. В соответствии с данной задачей разработаны программы по развитию определенных качеств и навыков, по усвоению широкого спектра знаний через игрофикацию. Следующим этапом в применении ИКТ в системе образования США станет распространение устройств с «дополненной реальностью» и постепенным стиранием граней между виртуальным и реальным мирами, что несет определенную опасность, так как расширяет возможности манипулирования сознанием и поведением человека.

\section{Лumepamypa}

1. Top 20 countries with highest number of internet users. [Электронный pecypc]: Internet World Statistics. URL: http://www.internetworldstats.com/top20.htm/ (дата обращения: 10.07.2016).

2. Всемирный банк, 2016 год. Доклад о мировом развитии-2016. [Электронный ресурс]: Обзор. Всемирный банк, Вашингтон, округ Колумбия. 58 с. URL: https://openknowledge.worldbank.org/ (дата обращения: 18.01.2016).

3. Тагунова И. А. Развитие наднационального образования в условиях глобализации. // Новое в психолого-педагогических исследованиях, 2008. № 1. С. 75-84.

4. Skills for Social Progress. The Power of Social and Emotional Skills. [Электронный pecypc]: OECD 10 Mar. 2015- pages:140. URL:www.oecd-library.org/education/skills-for-social-progress_9789264226159-en/ (дата обращения: 11.06.2016). 
5. President Obama's ConnectED initiative. June 06,2013. [Электронный pecypc]: URL: https://www.whitehouse.gov/the-press-office/2013/06/06/prezident-obama-unveils-connected-initiativebring-america-s-students-di./ (дата обращения: 25.06.2014).

6. Suvorova I. Не все сразу: что наука говорит о многозадачности. [Электронный ресурс]: Theory and Practice.Oct 29, 2014. URL: theoryandpractice.ru/posts/9745=multitasking./ (дата обращения: 20.03.2015).

7. How Snapchat Built a Business. [Электронный pecypc]: Bloomberg Businessweek.March 7, 2016. URL:www.bloomberg.com/features /2016-how-snapchat-built-a-business./ (дата обращения:14.03.2016).

8. Top 10 Education Gamification Examples that will Literally Save the World. (Электронный pecypc): URL: yukaichou.com/gamification-examples/top-10-gamification-examples-human-race обращения:12.08.2016).

9. Shamash A. 5 Ways to Build Resilience Every Day. [Электронный pecypc]: Mindful, Aug. 2, 2016. URL: www.mindful.org/5-ways-build-resilience-every-day./ (дата обращения: 10.08.2016).

10. Coleman L. A. What Is Financial Literacy. [Электронный pecypc]: Edutopia, Oct. 13,2015. URL: www.edutopia.org/blog/what-is-financial-literacy-lennette-coleman./ (дата обращения: 22.11.2015).

11. Гоулман Д. Фокус. О внимании, рассеянности и жизненном успехе. M.: CORPUS, 2015. 384 с.

12. Веселова В. В. Мегатренды новейшего времени - наше завтра? Или уже сегодня? [Электронный pecypc]: Российско-американский форум образования: электронный журнал. Vol: 7, Issue: 3. 15/12/2015. URL: www.rus - ameeduforum.com/content/ru/?task=art\&article=1001151\&iid=23./ (дата обращения: 14.01.2016). 